OPEN ACCESS

Edited by:

Nuno Madeira,

University of Coimbra, Portugal

Reviewed by:

Sarah Galdiolo,

University of Mons, Belgium

Sophie Schweizer-Schubert,

University Hospital Heidelberg,

Germany

${ }^{*}$ Correspondence:

Julia Martini

julia.martini@tu-dresden.de

${ }^{\dagger}$ These authors share last authorship

Specialty section:

This article was submitted to

Mood Disorders,

a section of the journal

Frontiers in Psychiatry

Received: 12 November 2021

Accepted: 09 December 2021

Published: 20 January 2022

Citation:

Asselmann E, Garthus-Niegel S and

Martini J (2022) Personality and

Peripartum Changes in Perceived Social Support: Findings From Two

Prospective-Longitudinal Studies in

(Expectant) Mothers and Fathers.

Front. Psychiatry 12:814152.

doi: 10.3389/fpsyt.2021.814152

\section{Personality and Peripartum Changes in Perceived Social Support: Findings From Two Prospective-Longitudinal Studies in (Expectant) Mothers and Fathers}

\author{
Eva Asselmann ${ }^{1}$, Susan Garthus-Niegel ${ }^{2,3,4+}$ and Julia Martini ${ }^{5,6 * t}$ \\ ${ }^{1}$ Faculty of Health, HMU Health and Medical University, Potsdam, Germany, ${ }^{2}$ Faculty of Medicine, Medical School Hamburg, \\ Institute for Systems Medicine (ISM), Hamburg, Germany, ${ }^{3}$ Faculty of Medicine, Institute and Policlinic of Occupational and \\ Social Medicine, Technische Universität Dresden, Dresden, Germany, ${ }^{4}$ Department of Child Health and Development, \\ Norwegian Institute of Public Health, Oslo, Norway, ${ }^{5}$ Faculty of Psychology, School of Science, Institute of Clinical \\ Psychology and Psychotherapy, Technische Universität Dresden, Dresden, Germany, ${ }^{6}$ Faculty of Medicine, Department of \\ Psychiatry and Psychotherapy, Carl Gustav Carus University Hospital, Technische Universität Dresden, Dresden, Germany
}

Objective: The aim of this study was to examine changes in perceived social support from early pregnancy to 2 years postpartum and to test whether these changes (a) differ between mothers and fathers or (b) vary as a function of the Big Five personality traits.

Background: Higher peripartum social support in (expectant) mothers and fathers has been associated with fewer complications during pregnancy and delivery as well as better parental and offspring health.

Methods: Prospective-longitudinal data from two regional-epidemiological samples from Germany were used: MARI ( $N=396$, including $n=293$ mothers and $n=103$ fathers) and DREAM ( $N=2,819$, including $n=1,689$ mothers and $n=1,130$ fathers). The Big Five personality traits were assessed during pregnancy in MARI as well as 8 weeks after the anticipated birth date in DREAM with short forms of the Big Five Inventory. Perceived social support was assessed during pregnancy, 4 months postpartum, and 16 months postpartum in MARI as well as during pregnancy, 14 months postpartum, and 2 years postpartum in DREAM using the short version of the Social Support Questionnaire.

Results: Multilevel analyses revealed that perceived social support decreased across the peripartum period, and this decrease did not differ between mothers and fathers. More extraverted, emotionally stable, agreeable, conscientious, and open parents perceived higher levels of social support across the peripartum period. The peripartum decrease of perceived social support was smaller in parents who were more extraverted.

Conclusion: Our findings suggest that especially extraversion plays an important role for high and stable levels of perceived social support across the peripartum period.

Implications: Particularly highly introverted parents might profit from targeted social support interventions.

Keywords: pregnancy, social support, personality, relationship processes, longitudinal, MARI study, DREAM study 


\section{INTRODUCTION}

Before and after the birth of a child, (expectant) mothers and fathers are faced with far-reaching life changes and new responsibilities (1-4). Social support from significant others (e.g., partners, parents, siblings, friends, colleagues, or health care professionals) during this challenging time plays an important role not only for their own well-being and functioning but also for the development of their offspring: Higher perceived social support during the peripartum period has been associated with better parental physical and mental health (5-7), fewer complications during pregnancy and delivery $(8,9)$, as well as more favorable developmental and health outcomes in the offspring (10). Conversely, lower social support has been linked to increased stress, anxiety, and depressive symptoms during pregnancy and after delivery $(5,7,11,12)$. Previous evidence even suggests that a lack of social support is one of the strongest environmental risk factors of postpartum depression (13-15).

Therefore, a major research task is to examine what contributes to high and stable levels of perceived social support across the peripartum period. Such research provides important cues for an early identification of high-risk groups of (expectant) parents as well as early targeted interventions to foster peripartum social support.

\section{Peripartum Changes in Perceived Social Support}

After the birth of a child, the social network size of new parents tends to decrease (16), while the intensity of support from close relatives (e.g., partner or parents) tends to increase (1719). Nonetheless, the gap between desired and actual support might widen after delivery due to new childcare responsibilities and parenting stress (and in turn less time to meet friends) (6). Consistent with this assumption, prospective-longitudinal studies found that perceived social support decreased across the transition to parenthood $(6,18,20)$. However, most of these studies focused on mothers, and little is known about peripartum changes in perceived social support in fathers.

\section{Gender Differences With Respect to Peripartum Changes in Perceived Social Support}

In line with traditional gender stereotypes (21), men might engage less in childcare than women. Therefore, fathers might experience less parenting stress and thus a smaller gap between desired and actual levels of support after childbirth than mothers. On the other hand, men still frequently function as the breadwinner of the family. Therefore, one could also speculate whether fathers feel less familiar with childcare and family issues, are more overwhelmed by their dual role, and thus perceive a greater lack of support after childbirth than mothers (22). Taken together, it is both plausible to assume that fathers experience a smaller or larger decrease of perceived social support after childbirth than mothers. Additional research is needed to resolve this question.

\section{The Role of Personality for Changes in Perceived Social Support Across the Peripartum Period}

Furthermore, levels and changes of perceived social support across the peripartum period might vary as a function of parents' personality. Personality refers to individual differences in thoughts, feelings, and behaviors (23) that can be described by the Big Five personality traits extraversion, emotional stability, agreeableness, conscientiousness, and openness to experience (24).

Previous research suggests that higher extraversion, emotional stability, agreeableness, conscientiousness, and openness relate to higher perceived social support (25). Extraverted individuals tend to be cheerful, energetic, outgoing, and socially active and experience more positive affect $(25,26)$. Thus, more extraverted mothers and fathers might handle challenging situations in family life more easily, need less social support, and experience their social support as more satisfactory (27). At the same time, more extraverted parents might have larger social networks (e.g., more friends) and better access to potential sources of support (5). Finally, they might be more likely to actively communicate their needs and directly seek for help, leading to higher levels of actual support in times of trouble.

Emotionally stable individuals tend to be resistant against stress and experience less negative affect $(25,26)$. Therefore, more emotionally stable mothers and fathers might have fewer difficulties to adjust to the new family situation $(5,28-30)$. They might cope with hassles due to a lack of sleep and lower autonomy more easily, require less help from others, and perceive their social support as less deficient.

Agreeable individuals are compliant, kind, and supportive (25). Because these characteristics tend to be beneficial in close relationships (27), more agreeable mothers and fathers might have stronger ties to their partner, close relatives, and friends and receive more social support during the peripartum period (31).

Conscientious individuals are careful, competent, diligent, and organized. Moreover, higher conscientiousness relates to higher mastery and more effective self-regulation $(26,32)$. Thus, more conscientious mothers and fathers might re-structure their daily routines and manage their new responsibilities more effectively and need less support. At the same time, more conscientious individuals might act more reliably toward others, which might foster secure relationships and reliable support.

Individuals who score high on openness tend to be openminded, adventurous, and creative $(33,34)$. Therefore, more open mothers and fathers might "embrace" their new role more, find unconventional ways to cope with stress, and need less support (35). In addition, their social networks might be more diverse, providing different sources of support (e.g., instrumental and emotional) for different problems.

Taken together, prior findings suggest that (a) perceived social support tends to decrease from pregnancy to postpartum and that (b) higher extraversion, emotional stability, agreeableness, conscientiousness, and openness relate to higher levels of perceived support. However, whether these personality characteristics relate to more favorable changes in perceived 
social support across the peripartum period (i.e., a greater increase or smaller decrease of support) remains an open question so far.

\section{Aims of the Study}

We used data from two prospective-longitudinal studies to examine changes in perceived social support from early pregnancy to 2 years postpartum and to test whether these changes (a) differ between mothers and fathers or (b) vary as a function of the Big Five personality traits. We hypothesized that social support decreases from pregnancy to postpartum and that this decrease is smaller in more extraverted, emotionally stable, agreeable, conscientious, and open parents. Gender differences between mothers and fathers were tested exploratorily. The findings from both studies were compared to evaluate the replicability, robustness, and reproducibility of the effects (36).

\section{METHODS}

Prospective-longitudinal data from two regional-epidemiological samples (MARI and DREAM) were combined.

\section{MARI}

The Maternal Anxiety in Relation to Infant Development (MARI) Study is a prospective-longitudinal regionalepidemiological study in (expectant) mothers and their partners from the area of Dresden, Germany (01/2009-09/2012). The study objective was to investigate the role of anxiety and depressive disorders prior to, during, and after pregnancy for perinatal outcomes, maternal health, and offspring development. Seven assessment waves with standardized diagnostic interviews, questionnaires, and observations were conducted: T1 (baseline, week 10-12 of gestation), T2 (week 22-24 of gestation), T3 (week 35-37 of gestation), T4 (10 days postpartum), T5 (2 months postpartum), T6 (4 months postpartum), and T7 (16 months postpartum). More detailed information on the aims, methods, design, and inclusion/ exclusion criteria of the MARI study, including a detailed study flow chart, has been presented elsewhere (37-39).

Informed consent was obtained from all participants. The study was approved by the Ethics Committee of the Faculty of Medicine of the Technische Universität Dresden (No: EK 94042007) and carried out in accordance with the Helsinki Declaration of 1975, as revised in 2008 and 2013.

\section{Sample of (Expectant) Mothers}

Overall, 533 expectant mothers were sampled from 22 gynecological outpatient settings in and around Dresden, Germany, and screened for inclusion and exclusion criteria. Fifty women were not enrolled due to the following exclusion criteria: Gestational age $>12$ weeks $(N=8)$; age $<18$ or $>$ 40 years $(N=8)$; multiple pregnancy $(N=2)$; history of more than three spontaneous abortions, (induced) termination of the pregnancy, still birth, or infant impairment $(N=2)$; invasive fertility treatment $(N=9)$; severe physical disease, microsomia, or skeletal malformation $(N=6)$; substance abuse or heroin substitution during the past 6 months $(N=0)$; severe psychiatric illness $(N=2)$; expectation to leave the area of Dresden $(N=$ $6)$; insufficient German skills $(N=7)$. Nine women did not participate due to spontaneous abortions before T1, 10 because their partner did not agree, 154 due to a lack of time, and four due to unknown reasons.

Finally, 306 expectant mothers were enrolled in the study, and 274 were retained until T7 (retention rate: $89.5 \%$ ). The participation of eight women ended after T1 due to a spontaneous abortion or termination of the pregnancy. During the study, three women moved away from the area of Dresden, five women could not be reached anymore by phone, postal, or personal contact, nine women reported a lack of time or interest in further participation, and seven women refused to be contacted again for further follow-up assessments. Some retained women did not participate in single assessments, for example, due to a preterm delivery, sickness, or a lack of time. Detailed information on sociodemographic, gynecological, and clinical characteristics of the sample of mothers has been previously published $(38,39)$.

\section{Sample of (Expectant) Fathers}

From week 22 to 24 of gestation, all 306 expectant mothers were asked whether the study personnel may approach their partner to participate in the study, and 134 (43.8\%) indicated that their partner may be contacted by phone. Of these partners, 109 met the inclusion criteria (sufficient German skills as well as willingness and time to participate) and agreed to participate. All 109 partners were men. In total, 109 (expectant) fathers participated at T2, 96 at T5, 91 at T6, and 26 at T7.

(Expectant) mothers with $(N=109)$ and without $(N=197)$ a participating partner differed in terms of sociodemographic, psychosocial, and neonatal characteristics (37). Specifically, expectant mothers with (vs. without) a participating partner were younger, better educated, and more often primiparous. Moreover, women with (vs. without) a participating partner reported higher postpartum levels of social support and a better partnership quality (37).

\section{DREAM}

The Dresden Study on Parenting, Work, and Mental Health ("DResdner Studie zu Elternschaft, Arbeit und Mentaler Gesundheit," DREAM) is a prospective-longitudinal cohort study in (expectant) mothers and their partners, recruited from June 2017 to the end of 2020 from the area of Dresden, Germany (06/2017-ongoing). The study objective was to prospectively examine the association between parental work participation, role distribution, and stress across the peripartum period, including their effects on perinatal outcomes and family health. So far, six questionnaire-based assessment waves are being conducted: T1 (baseline, during pregnancy, finished), T2 (8 weeks after the anticipated birth date), T3 (14 months postpartum), T4 (2 years postpartum), T5 (3 years postpartum), and T6 (4.5 years postpartum, starting in the end of 2021). More detailed information on the aims, methods, design, and inclusion/ exclusion criteria of the DREAM study, including a detailed study flow chart, has been published elsewhere (40). 
Informed consent was obtained from all participants. The study was approved by the Ethics Committee of the Faculty of Medicine of the Technische Universität Dresden (No: EK 278062015) and carried out in accordance with the Helsinki Declaration of 1975, as revised in 2008 and 2013. The data were collected and are managed using Research Electronic Data Capture (REDCap), hosted at the "Koordinierungszentrum für Klinische Studien" at the Faculty of Medicine of the Technische Universität Dresden $(41,42)$.

\section{Sample}

Expectant mothers and their partners were recruited during pregnancy, predominately at information sessions in hospitals and birth preparation courses in and around Dresden, Germany. Inclusion criteria were a current pregnancy, being a resident in the Dresden area, and sufficient German skills to complete the study questionnaires. Specific sub-groups (e.g., women with multiple pregnancies and same-sex couples) were not excluded to obtain a diverse sample and maximize the generalizability to the general population of expectant parents. The data collection of the DREAM study is currently still ongoing except for T1. Thus, the sample sizes from T2 onwards do not reflect the finally retained participants but only refer to those parents who have been due at the time of the data extraction. The current study is based on version 8 of the quality-assured data files, released for research in March 2021. Based on this version, 2,209, 1,967, 1,428, and 797 mothers as well as 1,608, 1,343, 969, and 544 partners participated at T1, T2, T3, and T4, respectively. Detailed information on sociodemographic, gynecological, and clinical sample characteristics has been presented elsewhere (40).

\section{Assessment of Personality}

In MARI, the Big Five were assessed at T2 (week 22-24 of gestation) with the German version of the BFI-K, the 21-item short form of the Big Five Inventory (43). The BFI-K contains five items for openness and four items for each of the other traits, labeled from $1=$ "strongly disagree" to $5=$ "strongly agree."

In DREAM, the Big Five were assessed at T2 (8 weeks after the anticipated birth date) with the German version of the BFI-S, the 15-item short form of the Big Five Inventory (John et al., 1991) $(44,45)$. The BFI-S contains three items per trait, labeled from $1=$ "strongly disagree" to $7=$ "strongly agree." The reliability and validity of the BFI-K (43) and BFI-S (46-49) have been supported previously. Both measures are well established and frequently used for the assessment of the Big Five.

\section{Assessment of Perceived Social Support}

Perceived social support was assessed in MARI at T2 (in week 22-24 of gestation), T6 (4 months postpartum), and T7 (16 months postpartum) and in DREAM at T1 (during pregnancy), T3 (14 months postpartum), and T4 (2 years postpartum) with the short version (K-14) of the Social Support Questionnaire (FSozU) Form A (50). The F-SozU Form A K-14 consists of 14 items (labeled 1 = "does not apply," 2 = "does rather not apply," 3 = "does partially apply," $4=$ "does apply," and $5=$ "does exactly apply"). These items refer to instrumental and emotional support, social integration, satisfaction with social support, and availability of confidants. The total score indicates participants' total levels of perceived social support. The internal consistency, test-retest reliability, as well as convergent and discriminant validity of the F-SozU have been shown to be good (50).

\section{Statistical Analyses}

Only individuals with information on personality (at T2 in MARI and DREAM) and perceived social support at any wave (at T2, T6, and/ or T7 in MARI and at T1, T3, and/ or T4 in DREAM) were considered. In MARI, this resulted in a total sample of 396 individuals $(N=293$ mothers and $N=103$ fathers). Specifically, 396 individuals ( $N=293$ mothers and $N=103$ fathers) provided information on perceived social support at T2, $358(N=281$ mothers and $N=77$ fathers $)$ at $\mathrm{T} 6$, and $280(N=255$ mothers and $N=25$ fathers) at T7.

In DREAM, this resulted in a sample of 3,172 individuals $(N$ $=1,897$ mothers and $N=1,275$ partners). Of these individuals, 335 were excluded because they did not complete T1 during (but after) pregnancy. In addition, 9 partners were excluded because they were female and 7 partners were excluded because they were not the biological father of the child. Finally, 14 individuals were excluded due to missing information on their date of birth. Thus, the final sample in DREAM consisted of 2,819 individuals ( $N=1,689$ mothers and $N=1,130$ fathers). Specifically, 2,819 individuals ( $N=1,689$ mothers and $N=1,130$ fathers) provided information on perceived social support at T1, 1,829 ( $N=1,122$ mothers and $N=707$ fathers $)$ at $\mathrm{T} 3$, and $914(N=556$ mothers and $N=358$ fathers) at T4.

The analyses were performed with Stata 14 (51). Multilevel analyses with measurement occasions (Level 1) nested within persons (Level 2) nested within couples (Level 3) were used. Specifically, we simultaneously regressed the perceived social support score (standardized across all waves) on age, gender, an early-postpartum variable, a late-postpartum variable, and two interaction terms (gender $\times$ early-postpartum and gender $\times$ late-postpartum). The early-postpartum variable was used to test for changes in perceived social support from pregnancy to early postpartum (i.e., 4 months postpartum in MARI and 14 months postpartum in DREAM). The late-postpartum variable was used to test for further changes in perceived social support until late postpartum (i.e., 16 months postpartum in MARI and 2 years postpartum in DREAM). The interaction terms (gender $\times$ early/ late-postpartum) were included to test whether these short- and long-term changes differed between mothers and fathers.

To test whether levels and changes in perceived social support varied by personality, we built the same model and additionally included (a) the respective Big Five trait as well as interaction terms of the respective Big Five trait with (b) gender, (c) the early-postpartum variable, and (d) the late-postpartum variable. A separate model was built for each Big Five trait to avoid multicollinearity. The interaction term with gender was used to test whether the role of the respective Big Five trait for perceived social support differed between mothers and fathers. The interaction terms with the early- and late-postpartum variable, respectively, were used to test whether the short- and/ or long-term changes in perceived social support varied by the respective Big Five trait. Table 1 summarizes how each predictor 
TABLE 1 | Description and coding of the predictors.

\begin{tabular}{|c|c|c|}
\hline Predictor & Used to examine... & Coding \\
\hline $\begin{array}{l}\text { Age } \\
\text { (Level } 2 \text { predictor) }\end{array}$ & Linear age effects & $\begin{array}{l}\text { - Age in years } \\
\text { - Centered across all waves }\end{array}$ \\
\hline $\begin{array}{l}\text { Gender } \\
\text { (Level } 2 \text { predictor) }\end{array}$ & $\begin{array}{l}\text { Differences in perceived } \\
\text { social support between } \\
\text { mothers and fathers }\end{array}$ & $\begin{array}{l}\text { - Coded with } 0 \text { in mothers and } 1 \\
\text { in fathers } \\
\text { - Centered across all waves }\end{array}$ \\
\hline $\begin{array}{l}\text { Early-postpartum } \\
\text { (Level } 1 \text { predictor) }\end{array}$ & $\begin{array}{l}\text { Changes in perceived } \\
\text { social support from } \\
\text { pregnancy to early } \\
\text { postpartum }\end{array}$ & $\begin{array}{l}\text { - Coded with } 1 \text { at T6 (4 months } \\
\text { postpartum) in MARI and T3 } \\
\text { (14 months postpartum) in } \\
\text { DREAM } \\
\text { - Coded with } 0 \text { at all other } \\
\text { waves }\end{array}$ \\
\hline $\begin{array}{l}\text { Late-postpartum } \\
\text { (Level } 1 \text { predictor) }\end{array}$ & $\begin{array}{l}\text { Changes in perceived } \\
\text { social support from } \\
\text { pregnancy/ early } \\
\text { postpartum to late } \\
\text { postpartum }\end{array}$ & $\begin{array}{l}\text { - Coded with } 1 \text { at T7 (16 months } \\
\text { postpartum) in MARI and T4 (2 } \\
\text { years postpartum) in DREAM } \\
\text { - Coded with } 0 \text { at all other } \\
\text { waves }\end{array}$ \\
\hline $\begin{array}{l}\text { Big Five trait } \\
\text { (Level } 2 \text { predictor) }\end{array}$ & Personality effects & $\begin{array}{l}\text { - Respective personality trait } \\
\text { score (extraversion, emotional } \\
\text { stability, agreeableness, } \\
\text { conscientiousness, } \\
\text { openness, respectively) } \\
\text { - Standardized across all waves }\end{array}$ \\
\hline
\end{tabular}

Multilevel analyses with measurement occasions (Level 1) nested within persons (Level 2) nested within couples (Level 3) were used.

was defined and coded. The alpha level was set at.05. Because each analysis refers to another research question, we did not control for multiple testing (52).

\section{RESULTS}

\section{Sample Characteristics}

Baseline sample characteristics for mothers and fathers of the MARI and DREAM sample are shown in Tables 2, 3. In MARI, the correlation of perceived social support during pregnancy with perceived social support 4 months and 16 months postpartum was $r=0.75$ and $r=0.68$, respectively. The correlation of perceived social support 4 months and 16 months postpartum was $r=0.74$. Perceived social support during pregnancy was slightly higher in parents who $\operatorname{did}(M=4.39, S D=0.52)$ vs. did not $(M=4.24, S D=0.60)$ participate in the study from pregnancy until 16 months postpartum, $t_{(394)}=-2.48, p=0.013$. That is, participants with lower initial levels of perceived social support were more likely to drop out.

In DREAM, the correlation of perceived social support during pregnancy with perceived social support 14 months and 2 years postpartum was $r=0.72$ and $r=0.65$, respectively. The correlation of perceived social support 14 months and 2 years postpartum was $r=0.72$. Perceived social support during pregnancy did not differ significantly between parents who did $(M=4.30, S D=0.59)$ and $\operatorname{did}$ not $(M=4.28, S D=0.60)$ participate until 2 years postpartum, $t_{(2,817)}=-0.56, p>0.05$. That is, attrition did not vary by initial levels of perceived social support.
TABLE 2 | Baseline sample characteristics of the MARI sample $(N=396)$.

\begin{tabular}{|c|c|c|c|c|}
\hline \multirow{2}{*}{$\begin{array}{l}\text { Sample characteristic } \\
\text { Age }(M, S D)\end{array}$} & \multicolumn{2}{|c|}{$\begin{array}{l}\text { (Expectant) mothers } \\
\qquad(N=293)\end{array}$} & \multicolumn{2}{|c|}{$\begin{array}{l}\text { (Expectant) fathers } \\
\qquad(N=103)\end{array}$} \\
\hline & 28.06 & 4.41 & 31.32 & 5.88 \\
\hline \multicolumn{5}{|l|}{ Education (N, \%) } \\
\hline No degree or 9th grade & 20 & 6.83 & 7 & 6.80 \\
\hline 10th grade & 74 & 25.26 & 25 & 24.27 \\
\hline High school & 106 & 36.18 & 31 & 30.10 \\
\hline University & 93 & 31.74 & 40 & 38.83 \\
\hline \multicolumn{5}{|l|}{ Marital status (N, \%) } \\
\hline Married & 106 & 36.18 & 41 & 39.81 \\
\hline Never married & 177 & 60.41 & 58 & 56.31 \\
\hline $\begin{array}{l}\text { Separated/ widowed/ } \\
\text { divorced }\end{array}$ & 10 & 3.41 & 4 & 3.88 \\
\hline \multicolumn{5}{|l|}{ Working time (N, \%) } \\
\hline Full-time & 116 & 39.59 & 75 & 72.82 \\
\hline Part-time & 80 & 27.30 & 5 & 4.85 \\
\hline Currently not working & 97 & 33.11 & 23 & 22.33 \\
\hline \multicolumn{5}{|l|}{$\begin{array}{l}\text { Monthly household } \\
\text { income } \\
\text { after taxes }(N, \%)\end{array}$} \\
\hline$<500$ Euros & 21 & 7.17 & 9 & 8.74 \\
\hline 500-1,000 Euros & 103 & 35.15 & 42 & 40.78 \\
\hline 1,500-2,500 Euros & 91 & 31.06 & 29 & 28.16 \\
\hline 2,500-3,500 Euros & 53 & 18.09 & 15 & 14.56 \\
\hline $3,500-4,500$ Euros & 18 & 6.14 & 6 & 5.83 \\
\hline More than 4,500 Euros & 7 & 2.39 & 2 & 1.94 \\
\hline \multicolumn{5}{|l|}{$\begin{array}{l}\text { Big Five traits at T2 (M, } \\
S D)\end{array}$} \\
\hline Extraversion & 3.60 & 0.83 & 3.31 & 0.87 \\
\hline Emotional stability & 3.36 & 0.79 & 3.68 & 0.71 \\
\hline Agreeableness & 3.35 & 0.67 & 3.31 & 0.72 \\
\hline Conscientiousness & 3.83 & 0.58 & 3.75 & 0.57 \\
\hline Openness & 3.78 & 0.63 & 3.74 & 0.75 \\
\hline
\end{tabular}

$M$, mean; $S D$, standard deviation.

\section{Peripartum (Changes in) Perceived Social Support in Mothers and Fathers}

Means and standard deviations for perceived social support at different assessment waves in the MARI and DREAM sample are shown in Table 4. In both samples, perceived social support was lower in fathers vs. mothers (MARI: $\beta=-0.25$, DREAM: $\beta=-0.15$; Table 5). Perceived social support decreased from pregnancy to early postpartum (i.e., 4 months postpartum in MARI: $\beta=-0.09$; 14 months postpartum in DREAM: $\beta=$ -0.18 ), and decreased further until late postpartum (i.e., 16 months postpartum in MARI: $\beta=-0.15 ; 2$ years postpartum in DREAM: $\beta=-0.19)$. The interactions with gender were not significant (all $p$-values $>0.05$ ). That is, neither in MARI nor in DREAM, these changes differed between (expectant) mothers and fathers.

\section{The Role of Personality}

Examining the role of personality revealed positive main effects for each of the Big Five personality traits in both studies 
TABLE 3 | Baseline sample characteristics of the DREAM sample $(N=2,819)$.

\begin{tabular}{|c|c|c|c|c|}
\hline \multirow{2}{*}{$\begin{array}{l}\text { Sample characteristic } \\
\text { Age }(M, S D)\end{array}$} & \multicolumn{2}{|c|}{$\begin{array}{l}\text { (Expectant) mothers } \\
\quad(N=1,689)\end{array}$} & \multicolumn{2}{|c|}{$\begin{array}{l}\text { (Expectant) fathers } \\
(N=1,130)\end{array}$} \\
\hline & 30.24 & 3.98 & 32.59 & 4.95 \\
\hline \multicolumn{5}{|l|}{ Education (N, \%) } \\
\hline No degree or 9th grade & 15 & 0.89 & 39 & 3.45 \\
\hline 10th grade & 344 & 20.37 & 262 & 23.19 \\
\hline High school & 365 & 21.61 & 210 & 18.58 \\
\hline University & 953 & 56.42 & 606 & 53.63 \\
\hline Other/unknown/missing data & 12 & 0.71 & 13 & 1.15 \\
\hline \multicolumn{5}{|l|}{ Marital status (N, \%) } \\
\hline Married & 752 & 44.52 & 531 & 46.99 \\
\hline Unmarried & 892 & 52.81 & 557 & 49.29 \\
\hline Widowed/divorced & 41 & 2.43 & 38 & 3.36 \\
\hline Unknown/missing data & 4 & 0.24 & 4 & 0.35 \\
\hline \multicolumn{5}{|l|}{ Working time $(N, \%)$} \\
\hline Full-time & 767 & 45.41 & 956 & 84.6 \\
\hline Part-time & 259 & 15.33 & 82 & 7.26 \\
\hline Irregular & 40 & 2.37 & 30 & 2.65 \\
\hline School/ university/ training & 64 & 3.79 & 35 & 3.1 \\
\hline Currently not working & 472 & 27.95 & 13 & 1.15 \\
\hline Other/unknown/missing data & 87 & 5.15 & 14 & 1.24 \\
\hline \multicolumn{5}{|l|}{$\begin{array}{l}\text { Monthly individual income } \\
\text { after taxes }(N, \%)\end{array}$} \\
\hline$\leq 450$ Euros & 53 & 3.14 & 25 & 2.21 \\
\hline 451-850 Euros & 46 & 2.72 & 12 & 1.06 \\
\hline $851-1,500$ Euros & 392 & 23.21 & 154 & 13.63 \\
\hline $1,501-2,500$ Euros & 890 & 52.69 & 612 & 54.16 \\
\hline$>2,500$ Euros & 216 & 12.79 & 281 & 24.87 \\
\hline Other/ unknown/ missing data & 92 & 5.45 & 46 & 4.07 \\
\hline \multicolumn{5}{|l|}{ Big Five traits at $\mathrm{T} 2(M, S D)$} \\
\hline Extraversion & 4.75 & 1.32 & 4.68 & 1.31 \\
\hline Emotional stability & 4.23 & 1.23 & 4.92 & 1.14 \\
\hline Agreeableness & 5.45 & 0.91 & 5.33 & 0.88 \\
\hline Conscientiousness & 5.62 & 0.93 & 5.31 & 0.95 \\
\hline Openness & 4.70 & 1.22 & 4.70 & 1.13 \\
\hline
\end{tabular}

$M$, mean; $S D$, standard deviation.

(Table 6): Higher extraversion (MARI: $\beta=0.35$, DREAM: $\beta=0.27$ ), emotional stability (MARI: $\beta=0.30$, DREAM: $\beta=0.19$ ), agreeableness (MARI: $\beta=0.23$, DREAM: $\beta=$ 0.17 ), conscientiousness (MARI: $\beta=0.18$, DREAM: $\beta=0.07$ ), and openness (MARI: $\beta=0.10$, DREAM: $\beta=0.12$ ) were associated with higher levels of perceived social support across the peripartum period. The interactions with gender were not significant (all $p$-values $>0.05$ ). That is, neither in MARI nor in DREAM, these changes differed between mothers and fathers.

In DREAM, there was a significant interactive effect between extraversion and the early-postpartum variable $(\beta=0.04)$, indicating that more extraverted parents experienced a smaller decrease of perceived social support from pregnancy to 14 months postpartum. However, no such interactive effect was found in MARI ( $p$-value $>0.05$ ). Moreover, there was no evidence that any other peripartum changes in perceived social support varied as a function of the Big Five personality traits (all $p$ values $>0.05)$.

\section{DISCUSSION}

These analyses based on data from two prospective-longitudinal studies aimed to examine (a) how perceived social support changes across the peripartum period in (expectant) mothers and fathers and (b) whether these changes vary by personality. Our main findings were that both mothers and fathers experienced a decrease of perceived social support from pregnancy to early and late postpartum. More extraverted, emotionally stable, agreeable, conscientious, and open individuals perceived higher levels of peripartum social support. In parents who scored higher on extraversion, the peripartum decrease of perceived social support was smaller.

First, we found that fathers experienced lower levels of perceived social support compared to mothers. As suggested by previous research (53), men might have fewer emotionally close relationships than women and thus fewer sources of support. In line with traditional gender stereotypes (21), fathers might also less often ask for help and be perceived as less vulnerable than mothers (54), which could lead to lower levels of actual social support. Compared to women, men still function more frequently as the breadwinner of the family. Therefore, they might on average feel less familiar with childcare and family issues and tend to be overwhelmed more by their dual role (22). Taken together, these potential reasons might explain why father experienced lower overall levels of perceived social support compared to mothers.

Second, our findings revealed that perceived social support decreased from pregnancy to early postpartum and from early to late postpartum. These results are consistent with previous findings $(6,18,20)$ and might be explained by higher childcare and parenting responsibilities after delivery. These responsibilities and associated distress might accumulate and lead to a larger gap between desired and actual support over time (6). Our findings considerably extend previous research because we considered both women and men and showed that not only mothers but also fathers perceived a decrease of social support across the peripartum period. Thus, it is plausible to assume that both women and men tend to feel overwhelmed by their new parental role after childbirth and thus experience a larger discrepancy between desired and actual levels of support during this challenging time.

Third, we found that more extraverted, emotionally stable, agreeable, conscientious, and open parents felt socially better supported across the peripartum period. As suggested by previous research, higher levels on these traits relate to a range of cognitive, emotional, and interpersonal skills (5, 26, 55), which could ease the transition to parenthood and explain our results. For example, more extraverted parents might have more friends and more agreeable parents more intimate relationships, leading to higher support in the first months postpartum. Emotionally stable mothers and fathers might be particularly resistant against stress, conscientious parents might re-organize their daily routines more effectively, and open individuals might find smart and creative solutions in challenging family situations. Taken together, these mechanisms might lead to a lower need of support (e.g., due to better problem-solving abilities) and higher actual support (e.g., due to closer social relationships) (25). 


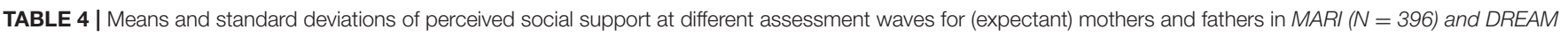
$(N=2,819)$.

\begin{tabular}{|c|c|c|c|c|c|c|c|c|c|c|c|c|}
\hline & \multicolumn{12}{|c|}{ Perceived social support } \\
\hline & \multicolumn{6}{|c|}{ MARI $(N=396)$} & \multicolumn{6}{|c|}{ DREAM $(N=2,819)$} \\
\hline & \multicolumn{2}{|c|}{$\mathrm{T} 2(N=396)$} & \multicolumn{2}{|c|}{ T6 $(N=358)$} & \multicolumn{2}{|c|}{$\mathrm{T7}(N=280)$} & \multicolumn{2}{|c|}{$\mathrm{T} 1(N=2,819)$} & \multicolumn{2}{|c|}{ T3 $(N=1,829)$} & \multicolumn{2}{|c|}{ T4 $(N=914)$} \\
\hline & $\mathbf{M}$ & SD & M & SD & M & SD & M & SD & M & SD & M & SD \\
\hline Total sample & 4.34 & 0.55 & 4.30 & 0.61 & 4.31 & 0.59 & 4.29 & 0.60 & 4.17 & 0.69 & 4.17 & 0.70 \\
\hline (Expectant) mothers & 4.37 & 0.53 & 4.33 & 0.62 & 4.32 & 0.59 & 4.33 & 0.57 & 4.23 & 0.66 & 4.22 & 0.67 \\
\hline (Expectant) fathers & 4.25 & 0.60 & 4.19 & 0.54 & 4.17 & 0.60 & 4.22 & 0.63 & 4.07 & 0.73 & 4.10 & 0.73 \\
\hline
\end{tabular}

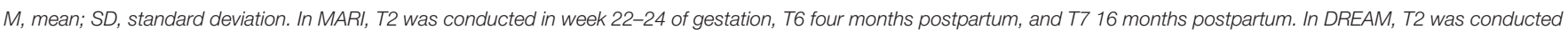
during pregnancy, T3 14 months postpartum, and T4 two years postpartum.

TABLE 5 | Peripartum (changes in) perceived social support, including differences between (expectant) mothers and fathers, in MARI ( $N=396)$ and DREAM $(N=2,819)$.

\begin{tabular}{|c|c|c|c|c|c|c|c|c|}
\hline \multirow[b]{4}{*}{ Gender (fathers vs. mothers) } & \multicolumn{8}{|c|}{ Perceived social support } \\
\hline & \multicolumn{4}{|c|}{ MARI $(N=396)$} & \multicolumn{4}{|c|}{ DREAM $(N=2,819)$} \\
\hline & \multirow{2}{*}{$\begin{array}{c}\beta \\
-0.25\end{array}$} & \multicolumn{2}{|c|}{$95 \% \mathrm{Cl}$} & \multirow{2}{*}{$\begin{array}{c}p \\
0.025\end{array}$} & \multirow{2}{*}{$\begin{array}{c}\beta \\
-0.15\end{array}$} & \multicolumn{2}{|c|}{$95 \% \mathrm{Cl}$} & \multirow{2}{*}{$\begin{array}{c}p \\
<0.001\end{array}$} \\
\hline & & -0.47 & -0.03 & & & -0.21 & -0.08 & \\
\hline Early-postpartum & -0.09 & -0.17 & -0.02 & 0.018 & -0.18 & -0.22 & -0.15 & $<0.001$ \\
\hline Gender $\times$ late-postpartum & -0.12 & -0.39 & 0.15 & 0.392 & -0.04 & -0.13 & 0.06 & 0.444 \\
\hline
\end{tabular}

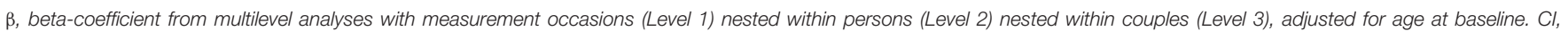

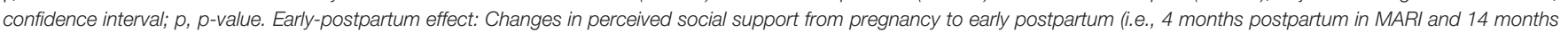

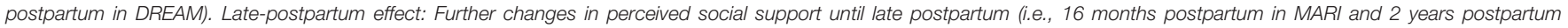
in DREAM). Significant effects $(p<0.05)$ are printed in bold.

Fourth, our findings particularly emphasize the importance of extraversion. Extraversion was not only the strongest predictor of perceived social support but also predicted a smaller peripartum decrease of perceived social support. In this regard, it is plausible to assume that more extraverted individuals not only have a larger social network (25). They might also be able to communicate their needs more clearly and actively ask for help from family members, friends, physicians, and childcare professionals (25). In addition, more extraverted mothers and fathers might profit from higher levels of positive affect and social leisure activities in everyday life, which could buffer parenting stress (26).

Finally, our findings were nearly identical for both samples, which underlines the replicability of our results. This fact is particularly noteworthy given the "replication crisis" and increasing claims for more replicable, robust, and reproducible research in psychological science (36). However, the interactive effect with extraversion was found in the DREAM but not in the MARI sample, which might be due to the larger sample size.

\section{Strengths and Limitations}

Our work has several strengths: We used data from two prospective-longitudinal studies in expectant parents. In both studies, the Big Five personality traits were assessed with the BFI, and perceived social support was assessed repeatedly from early pregnancy to late postpartum with the FSozU, a wellestablished questionnaire. Our findings were highly similar in both samples, which emphasizes the replicability, robustness, and reproducibility of the results.

Nonetheless, the following limitations should be mentioned: First, personality was assessed with the BFI-K (MARI) and BFI$S$ (DREAM) - short questionnaires that are less comprehensive than longer measures and, for example, do not allow to distinguish between different facets of the Big Five. Second, in DREAM, personality (T2) was assessed after the first assessment of perceived social support (T1), and personality might have changed from T1 to T2. However, the Big Five traits are considered to be relatively stable over short periods of time (56-59). Third, not all parents of the respective baseline sample participated until the last assessment of perceived social support, and systematic drop out might have occurred $(38,39)$. For example, especially parents with low and decreasing levels of perceived support might have ended their participation earlier, which could have led to an underestimation of peripartum changes in perceived social support (6). Fourth, in both studies, more mothers than fathers participated, and drop out was also lower in mothers vs. fathers. In MARI, participating fathers were approached indirectly via participating mothers, which might have doubled selection effects and, for example, might have led to an overrepresentation of particularly engaged fathers (37). Fifth, we focused on peripartum changes in general social support (e.g., from family members, friends, colleagues, or health professionals), considering the role of 
TABLE 6 | Associations of the Big Five personality traits with peripartum (changes in) perceived social support in MARI $(N=396)$ and DREAM $(N=2,819)$.

\begin{tabular}{|c|c|c|c|c|c|c|c|c|}
\hline \multirow{4}{*}{$\begin{array}{l}\text { Predictor } \\
\text { Extraversion (main effect) }\end{array}$} & \multicolumn{8}{|c|}{ Perceived social support } \\
\hline & \multicolumn{4}{|c|}{ MARI $(N=396)$} & \multicolumn{4}{|c|}{ DREAM $(N=2,819)$} \\
\hline & \multirow{2}{*}{$\begin{array}{l}\beta \\
0.35\end{array}$} & \multicolumn{2}{|c|}{$95 \% \mathrm{Cl}$} & \multirow{2}{*}{$\begin{array}{c}p \\
<0.001\end{array}$} & \multirow{2}{*}{$\begin{array}{l}\beta \\
0.27\end{array}$} & \multicolumn{2}{|c|}{$95 \% \mathrm{Cl}$} & \multirow{2}{*}{$\frac{p}{<0.001}$} \\
\hline & & 0.26 & 0.44 & & & 0.24 & 0.30 & \\
\hline Extraversion $\times$ gender & 0.04 & -0.14 & 0.23 & 0.643 & 0.03 & -0.03 & 0.10 & 0.279 \\
\hline Extraversion $\times$ early-postpartum & 0.03 & -0.04 & 0.11 & 0.414 & 0.04 & 0.01 & 0.08 & 0.011 \\
\hline Extraversion $\times$ late-postpartum & 0.05 & -0.04 & 0.13 & 0.265 & 0.02 & -0.03 & 0.06 & 0.515 \\
\hline Emotional stability (main effect) & 0.30 & 0.21 & 0.40 & $<0.001$ & 0.19 & 0.15 & 0.22 & $<0.001$ \\
\hline Emotional stability $\times$ gender & 0.14 & -0.07 & 0.35 & 0.204 & -0.01 & -0.08 & 0.06 & 0.754 \\
\hline Emotional stability $\times$ early-postpartum & 0.01 & -0.07 & 0.09 & 0.829 & 0.01 & -0.03 & 0.04 & 0.643 \\
\hline Emotional stability $\times$ late-postpartum & 0.05 & -0.03 & 0.13 & 0.253 & -0.01 & -0.06 & 0.04 & 0.748 \\
\hline Agreeableness (main effect) & 0.23 & 0.13 & 0.32 & $<0.001$ & 0.17 & 0.14 & 0.21 & $<0.001$ \\
\hline Agreeableness $\times$ gender & -0.18 & -0.37 & 0.01 & 0.064 & 0.04 & -0.03 & 0.10 & 0.268 \\
\hline Agreeableness $\times$ early-postpartum & 0.03 & -0.04 & 0.11 & 0.383 & -0.01 & -0.04 & 0.03 & 0.745 \\
\hline Agreeableness $\times$ late-postpartum & 0.00 & -0.09 & 0.08 & 0.943 & -0.03 & -0.08 & 0.01 & 0.141 \\
\hline Conscientiousness (main effect) & 0.18 & 0.08 & 0.28 & $<0.001$ & 0.07 & 0.03 & 0.11 & $<0.001$ \\
\hline Conscientiousness $\times$ gender & 0.04 & -0.16 & 0.25 & 0.680 & -0.06 & -0.12 & 0.01 & 0.088 \\
\hline Conscientiousness $\times$ early-postpartum & 0.00 & -0.08 & 0.08 & 0.988 & 0.01 & -0.03 & 0.04 & 0.624 \\
\hline Conscientiousness $\times$ late-postpartum & -0.02 & -0.11 & 0.06 & 0.611 & 0.01 & -0.04 & 0.06 & 0.660 \\
\hline Openness (main effect) & 0.10 & 0.00 & 0.20 & 0.042 & 0.12 & 0.09 & 0.16 & $<0.001$ \\
\hline Openness $\times$ gender & 0.16 & -0.02 & 0.34 & 0.088 & 0.05 & -0.01 & 0.12 & 0.114 \\
\hline Openness $\times$ early-postpartum & 0.00 & -0.08 & 0.07 & 0.980 & 0.02 & -0.01 & 0.06 & 0.193 \\
\hline Openness $\times$ late-postpartum & -0.05 & -0.13 & 0.04 & 0.278 & -0.01 & -0.06 & 0.03 & 0.533 \\
\hline
\end{tabular}

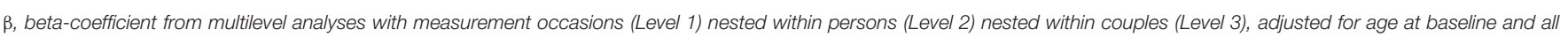

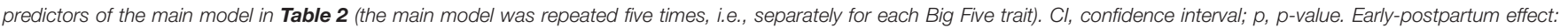

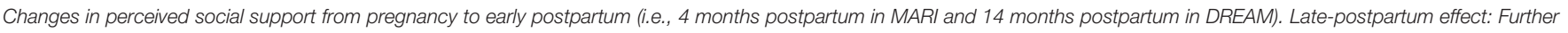
changes in perceived social support until late postpartum (i.e., 16 months postpartum in MARI and 2 years postpartum in DREAM). Significant effects ( $p<0.05$ ) are printed in bold.

gender and personality. Additional research could specifically focus on dyadic associations of partner support in participating couples, for instance, based on the actor-partner interdependence model (60). Sixth, our data stem from (expectant) parents in and around Dresden, Germany $(39,40)$. Thus, the generalizability to mothers and fathers in other regions might be limited.

\section{CONCLUSIONS}

Taken together, our findings suggest that especially extraversion plays an important role for high and stable levels of perceived social support across the peripartum period. Therefore, particularly highly introverted mothers and fathers might profit from targeted interventions. Such programs might promote specific skills to establish and maintain social contacts, communicate individual needs, and actively seek for support in stressful situations (7). Future research is needed to investigate the role of extraversion for perceived and actual levels of social support across the peripartum period in greater detail as well as to test the efficacy of targeted interventions. Moreover, future research could examine how romantic relationship characteristics contribute to peripartum changes in partner support and how (expectant) mothers and fathers influence each other reciprocally over time. Finally, the interplay of personality traits with predisposing vulnerabilities in parents at increased risk for mental disorders may be investigated in further detail.

\section{DATA AVAILABILITY STATEMENT}

The data of this study are not openly accessible because after consulting the Ethics Committee and due to the sensitive nature of the questions asked in this study, participants were assured that all raw data would remain confidential and not be shared. Further information on the data can be obtained from the corresponding author, the Ethics Committee of the Medical Faculty of the Technische Universitaet Dresden, and the Institute of Clinical Psychology and Psychotherapy of the Technische Universitaet Dresden. Requests to access the datasets should be directed to julia.martini@tu-dresden.de.

\section{ETHICS STATEMENT}

The studies involving human participants were reviewed and approved by the Ethics Committee of the Medical Faculty of the Technische Universitaet Dresden. All participants 
provided their written informed consent to participate in this study.

\section{AUTHOR CONTRIBUTIONS}

JM: conception and design of the MARI study and data collection MARI study. SG-N: conception and design of the DREAM study and data collection DREAM study. EA: data analysis and preparation of the manuscript. EA, SG-N, and JM: interpretation, critical review, and approval of the final manuscript. Principle investigator of the DREAM study is SG-N, who is a management committee member of COST action CA18211: DEVOTION: Perinatal Mental Health and Birth-Related Trauma: Maximizing best practice and optimal outcomes. All authors contributed to the article and approved the submitted version.

\section{FUNDING}

The MARI study was funded by the Institute of Clinical Psychology and Psychotherapy, Technische Universität Dresden, Germany, and supported in parts by the Lundbeck Institute Skodsborg, Denmark. Parts of the field work were additionally

\section{REFERENCES}

1. Asselmann E, Specht J. Testing the Social Investment Principle around childbirth: Little evidence for personality maturation before and after becoming a parent. Euro J Personal. (2021) 35:85-102. doi: 10.1002/per.2269

2. Asselmann E, Wittchen H-U, Petzoldt J, Martini J. Peripartum changes in partnership quality among women with and without anxiety and depressive disorders prior to pregnancy: a prospective-longitudinal study. Archiv Women's Ment Health. (2016) 19:281-90. doi: 10.1007/s00737-015-0556-6

3. Bleidorn W, Buyukcan-Tetik A, Schwaba T, Van Scheppingen MA, Denissen JJ, Finkenauer C. Stability and change in self-esteem during the transition to parenthood. Soc Psychol Personal Sci. (2016) 7:560-9. doi: $10.1177 / 1948550616646428$

4. van Scheppingen MA, Denissen JJ, Bleidorn W. Stability and change in selfcontrol during the transition to parenthood. Eur J Pers. (2018) 32:690-704. doi: $10.1002 /$ per.2172

5. Asselmann E, Kunas SL, Wittchen H-U, Martini J. Maternal personality, social support, and changes in depressive, anxiety, and stress symptoms during pregnancy and after delivery: a prospective-longitudinal study. PLOS ONE. (2020) 15:e0237609. doi: 10.1371/journal.pone.0237609

6. Asselmann E, Wittchen H-U, Erler L, Martini J. Peripartum changes in social support among women with and without anxiety and depressive disorders prior to pregnancy: a prospective-longitudinal study. Archiv Wom Ment Health. (2016) 19:943-52. doi: 10.1007/s00737-016-0608-6

7. Bedaso A, Adams J, Peng W, Sibbritt D. The relationship between social support and mental health problems during pregnancy: a systematic review and meta-analysis. Reprod Health. (2021) 18:1-23. doi: 10.1186/s12978-021-01209-5

8. Hetherington E, Doktorchik C, Premji SS, McDonald SW, Tough SC, Sauve RS. Preterm birth and social support during pregnancy: a systematic review and meta-analysis. Paediatr Perinat Epidemiol. (2015) 29:523-35. doi: $10.1111 /$ ppe. 12225

9. Orr ST. Social support and pregnancy outcome: a review of the literature. Clin Obstet Gynecol. (2004) 47:842-55. doi: 10.1097/01.grf.0000141451.68933.9f

10. Lee L-C, Halpern CT, Hertz-Picciotto I, Martin SL, Suchindran CM. Child care and social support modify the association between maternal depressive symptoms and early childhood behavior problems: a US national study. $J$ Epidemiol Commun Health. (2006) 60:305-10. doi: 10.1136/jech.2005.040956 supported by the Friends and Sponsors (Gesellschaft der Freunde und Förderer) of the Technische Universität Dresden, Germany. The DREAM study was funded by the German Research Foundation (Deutsche Forschungsgemeinschaft; DFG; Grant Numbers GA 2287/4-1 and GA 2287/4-2). This paper contributes to the EU COST Action 18211 supported by COST (European Cooperation in Science and Technology).

\section{ACKNOWLEDGMENTS}

Dr. Hans-Ulrich Wittchen is a principle investigator of the MARI study. Core staff members of the project are Dipl.-Psych. Yvonne Hansche, Dr. Michael Höfler, Dr. Johanna Petzoldt, Dipl.Math. Jens Strehle, Dr. Gesine Wieder, Dipl.-Psych. Susanne Müllender, and Dipl.-Psych. Julia Wittich. Advisors/consultants to the project are Prof. Dr. Katja Beesdo-Baum, Dr. Franziska Einsle, and Prof. Dr. Susanne Knappe. We would like to thank all mothers and fathers for spending their time and effort in our studies. We would also like to thank all cooperating clinics, physicians, and midwives for providing access to the potential participants and all student assistants and staff members for supporting our study.

11. Biaggi A, Conroy S, Pawlby S, Pariante CM. Identifying the women at risk of antenatal anxiety and depression: a systematic review. J Affect Disord. (2016) 191:62-77. doi: 10.1016/j.jad.2015.11.014

12. Racine N, Plamondon A, Hentges R, Tough S, Madigan S. Dynamic and bidirectional associations between maternal stress, anxiety, and social support: the critical role of partner and family support. J Affect Disord. (2019) 252:1924. doi: 10.1016/j.jad.2019.03.083

13. Beck CT. Predictors of postpartum depression: an update. Nurs Res. (2001) 50:275-85. doi: 10.1097/00006199-200109000-00004

14. Robertson E, Grace S, Wallington T, Stewart DE. Antenatal risk factors for postpartum depression: a synthesis of recent literature. Gen Hosp Psychiatry. (2004) 26:289-95. doi: 10.1016/j.genhosppsych.2004.02.006

15. Yim IS, Tanner Stapleton LR, Guardino CM, Hahn-Holbrook J, Dunkel Schetter C. Biological and psychosocial predictors of postpartum depression: systematic review and call for integration. Annu Rev Clin Psychol. (2015) 11:99-137. doi: 10.1146/annurev-clinpsy-101414-020426

16. Wrzus C, Hänel M, Wagner J, Neyer FJ. Social network changes and life events across the life span: a meta-analysis. Psychol Bull. (2013) 139:53-80. doi: 10.1037/a0028601

17. Belsky J, Rovine M. Social-network contact, family support, and the transition to parenthood. J Marriage Fam. (1984) 46:455-62. doi: 10.2307/352477

18. Bost KK, Cox MJ, Burchinal MR, Payne C. Structural and supportive changes in couples' family and friendship networks across the transition to parenthood. J Marriage Fam. (2002) 64:517-31. doi: 10.1111/j.1741-3737.2002.00517.x

19. McCannell K. "Social networks and the transition to motherhood," In: R. Milardo editor, Families and Social Networks Sage (1987).

20. Baker D, Taylor H, Team TAS. The relationship between conditionspecific morbidity, social support and material deprivation in pregnancy and early motherhood. Soc Sci Med. (1997) 45:1325-36. doi: 10.1016/S0277-9536(97)00059-2

21. Valiquette-Tessier S-C, Gosselin J, Young M, Thomassin K. A literature review of cultural stereotypes associated with motherhood and fatherhood. Marriage Fam Rev. (2019) 55:299-329. doi: 10.1080/01494929.2018.1469567

22. Baldwin S, Malone M, Sandall J, Bick D. Mental health and wellbeing during the transition to fatherhood: a systematic review of first time fathers' experiences. JBI Database Systematic Rev Implement Rep. (2018) 16:2118-91. doi: 10.11124/JBISRIR-2017-003773 
23. Allport GW. Pattern and growth in personality. Holt, Reinhart and Winston. (1961).

24. McCrae R, Costa P. "The five-factor theory of personality, In: O. P. John, R. W. Robins, and L. A. Pervin editor, Handbook of Personality: Theory and Research, London: The Guilford Press (2008).

25. Barańczuk U. The Five Factor Model of personality and social support: a meta-analysis. J Res Pers. (2019) 81:38-46. doi: 10.1016/j.jrp.2019.05.002

26. Anglim J, Horwood S, Smillie LD, Marrero RJ, Wood JK. Predicting psychological and subjective well-being from personality: a meta-analysis. Psychol Bull. (2020) 146:279-323. doi: 10.1037/bul0000226

27. Tov W, Nai ZL, Lee HW. Extraversion and agreeableness: Divergent routes to daily satisfaction with social relationships. J Pers. (2016) 84:121-34. doi: 10.1111 /jopy.12146

28. Richter D, Krämer MD, Tang NK, Montgomery-Downs HE, Lemola S. Longterm effects of pregnancy and childbirth on sleep satisfaction and duration of first-time and experienced mothers and fathers. Sleep. (2019) 42:zsz015. doi: 10.1093/sleep/zsz015

29. Roman M, Bostan CM, Diaconu-Gherasim LR, Constantin T. Personality traits and postnatal depression: the mediated role of postnatal anxiety and moderated role of type of birth. Front Psychol. (2019) 10:1625. doi: $10.3389 /$ fpsyg. 2019.01625

30. Schaber R, Karl M, Kopp M, Kress V, Weidner K, Martini J, et al. My job, my child, my house: the predictive value of job-and housework-related factors on depressive symptoms during the postpartum period. J Affect Disord. (2020) 272:388-97. doi: 10.1016/j.jad.2020.04.016

31. Branje SJ, van Lieshout CF, van Aken MA. Relations between Big Five personality characteristics and perceived support in adolescents' families. $J$ Pers Soc Psychol. (2004) 86:615-28. doi: 10.1037/0022-3514.86.4.615

32. Roberts BW, Lejuez C, Krueger RF, Richards JM, Hill PL. What is conscientiousness and how can it be assessed? Dev Psychol. (2014) 50:1315-30. doi: $10.1037 / \mathrm{a} 0031109$

33. Kandler C, Riemann R, Angleitner A, Spinath FM, Borkenau P, Penke L. The nature of creativity: the roles of genetic factors, personality traits, cognitive abilities, and environmental sources. J Pers Soc Psychol. (2016) 111:230-49. doi: $10.1037 /$ pspp0000087

34. McCrae RR. Creativity, divergent thinking, and openness to experience. J Pers Soc Psychol. (1987) 52:1258-65. doi: 10.1037/0022-3514.52.6.1258

35. Dyrdal GM, Lucas RE. Reaction and adaptation to the birth of a child: A couple-level analysis. Dev Psychol. (2013) 49:749-61. doi: 10.1037/a0028335

36. Nosek BA, Hardwicke TE, Moshontz H, Allard A, Corker KS, Almenberg $\mathrm{AD}$, et al. Replicability, robustness, and reproducibility in psychological science. Annu Rev Psychol. (2021) 19:114157. doi: 10.1146/annurev-psych-020821-114157

37. Knappe S, Petzoldt J, Garthus-Niegel S, Wittich J, Puls H-C, Huttarsch I, et al. Associations of partnership quality and father-to-child attachment during the peripartum period. a prospective-longitudinal study in expectant fathers. Front Psychiatr. (2021) 12:572755. doi: 10.3389/fpsyt.2021.572755

38. Martini J, Petzoldt J, Einsle F, Beesdo-Baum K, Höfler M, Wittchen H-U. Risk factors and course patterns of anxiety and depressive disorders during pregnancy and after delivery: a prospective-longitudinal study. J Affect Disord. (2015) 175:385-95. doi: 10.1016/j.jad.2015.01.012

39. Martini J, Wittich J, Petzoldt J, Winkel S, Einsle F, Siegert J, et al. Maternal anxiety disorders prior to conception, psychopathology during pregnancy and early infants' development: a prospective-longitudinal study. Archiv Women's Ment Health. (2013) 16:549-60. doi: 10.1007/s00737-013-0376-5

40. Kress V, Steudte-Schmiedgen S, Kopp M, Förster A, Altus C, Schier C, et al. The impact of parental role distributions, work participation, and stress factors on family health-related outcomes: study protocol of the prospective multi-method cohort "Dresden study on parenting, work, and mental health"(DREAM). Front Psychol. (2019) 10:1273. doi: $10.3389 /$ fpsyg. 2019.01273

41. Harris PA, Taylor R, Minor BL, Elliott V, Fernandez M, O’Neal L, et al. The REDCap consortium: Building an international community of software platform partners. J Biomed Inform. (2019) 95:103208. doi: 10.1016/j.jbi.2019.103208

42. Harris PA, Taylor R, Thielke R, Payne J, Gonzalez N, Conde JG. Research electronic data capture (REDCap) - a metadata-driven methodology and workflow process for providing translational research informatics support. $J$ Biomed Inform. (2009) 42:377-81. doi: 10.1016/j.jbi.2008.08.010
43. Rammstedt B, John OP. Kurzversion des Big Five Inventory (BFI-K). Diagnostica. (2005) 51:195-206. doi: 10.1026/0012-1924.51.4.195

44. John OP, Naumann LP, Soto CJ. Paradigm shift to the integrative big five trait taxonomy. Handbook Personal Theory Res. (2008) 3:114-58.

45. Lang FR, John D, Lüdtke O, Schupp J, Wagner GG. Short assessment of the Big Five: robust across survey methods except telephone interviewing. Behav Res Methods. (2011) 43:548-67. doi: 10.3758/s13428-011-0066-Z

46. Donnellan MB, Lucas RE. Age differences in the Big Five across the life span: evidence from two national samples. Psychol Aging. (2008) 23:558-66. doi: $10.1037 / \mathrm{a} 0012897$

47. Gerlitz JY, Schupp J. Zur Erhebung der Big-Five-basierten Persoenlichkeitsmerkmale im SOEP [The measurement of the Big Five personality traits in the SOEP] (Vol. 4). DIW Berlin (2005).

48. Hahn E, Gottschling J, Spinath FM. Short measurements of personalityValidity and reliability of the GSOEP Big Five Inventory (BFI-S). J Res Pers. (2012) 46:355-9. doi: 10.1016/j.jrp.2012.03.008

49. Lang FR. Erfassung des kognitiven Leistungspotenzials und der "Big Five" mit Computer-Assisted-Personal-Interviewing (CAPI): Zur Reliabilität und Validität zweier ultrakurzer Tests und des BFI-S [Assessment of cognitive capabilities and the Big Five with Computer-Assisted Personal Interviewing (CAPI): Reliability and validity]. DIW Research Notes (2005).

50. Fydrich T, Sommer G, Tydecks S, Brähler E. Fragebogen zur sozialen Unterstützung (F-SozU): Normierung der Kurzform (K-14) Social Support Questionnaire (F-SozU): Standardization of short form (K-14). Zeitschrift für Medizinische Psychologie. (2009) 18:43-8.

51. StataCorp. Stata Statistical Software: Release 14. StataCorp LP (2015).

52. Savitz DA, Olshan AF. Multiple comparisons and related issues in the interpretation of epidemiologic data. Am J Epidemiol. (1995) 142:904-8. doi: 10.1093/oxfordjournals.aje.a117737

53. Aukett R, Ritchie J, Mill K. Gender differences in friendship patterns. Sex Roles. (1988) 19:57-66. doi: 10.1007/BF00292464

54. Reevy GM, Maslach C. Use of social support: Gender and personality differences. Sex Roles. (2001) 44:437-59. doi: 10.1023/A:1011930128829

55. Asselmann E, Klimstra T, Denissen JJ. Unraveling resilience: Personality predicts exposure and reaction to stressful life events. Personal Sci. (2021) 2:6055. doi: $10.5964 /$ ps.6055

56. Epstein S. The stability of behavior: I. On predicting most of the people much of the time. J Personal Soc Psychol. (1979) 37:1097-126. doi: 10.1037/0022-3514.37.7.1097

57. Epstein S. The stability of behavior: II. implications for psychological research. Am Psychol. (1980) 35:790-806. doi: 10.1037/0003-066X.35.9.790

58. Kandler C, Zimmermann J, McAdams DP. Core and surface characteristics for the description and theory of personality differences and development. Eur $J$ Pers. (2014) 28:231-43. doi: 10.1002/per.1952

59. Steyer R, Schmitt M, Eid M. Latent state-trait theory and research in personality and individual differences. Eur J Pers. (1999) 13:389-408. doi: 10.1002/(SICI)1099-0984(199909/10)13:5389::AID-PER3613.0.CO;2-A

60. Cook WL, Kenny DA. The actor-partner interdependence model: A model of bidirectional effects in developmental studies. Int J Behav Dev. (2005) 29:101-9. doi: 10.1080/01650250444000405

Conflict of Interest: The authors declare that the research was conducted in the absence of any commercial or financial relationships that could be construed as a potential conflict of interest.

Publisher's Note: All claims expressed in this article are solely those of the authors and do not necessarily represent those of their affiliated organizations, or those of the publisher, the editors and the reviewers. Any product that may be evaluated in this article, or claim that may be made by its manufacturer, is not guaranteed or endorsed by the publisher.

Copyright $\odot 2022$ Asselmann, Garthus-Niegel and Martini. This is an open-access article distributed under the terms of the Creative Commons Attribution License (CC $B Y)$. The use, distribution or reproduction in other forums is permitted, provided the original author(s) and the copyright owner(s) are credited and that the original publication in this journal is cited, in accordance with accepted academic practice. No use, distribution or reproduction is permitted which does not comply with these terms. 